\title{
A potential role for adjunctive vitamin $D$ therapy in the management of weight gain and metabolic side effects of second-generation antipsychotics
}

\author{
Benjamin U. Nwosu ${ }^{1, *}$, Bruce Meltzer ${ }^{2}$, Louise \\ Maranda ${ }^{1}$, Carol Ciccarelli ${ }^{1}$, Daniel Reynolds ${ }^{2}$, Laura \\ Curtis², Jean King $^{2}$, Jean A. Frazier ${ }^{2}$ and \\ Mary M. Lee ${ }^{1}$ \\ ${ }^{1}$ Division of Pediatric Endocrinology, University of \\ Massachusetts Medical School, Worcester, MA, USA \\ ${ }^{2}$ Division of Child Psychiatry, University of \\ Massachusetts Medical School, Worcester, MA, USA
}

\begin{abstract}
Second-generation antipsychotic (SGA) medications introduced about 20 years ago are increasingly used to treat psychiatric illnesses in children and adolescents. There has been a five-fold increase in the use of these medications in U.S. children and adolescents in the past decade. However, there has also been a parallel rise in the incidence of side effects associated with these medications, such as obesity, dyslipidemia, insulin resistance, and diabetes mellitus. Despite the severity of these complications and their financial impact on the national healthcare budget, there is neither a clear understanding of the mechanisms contributing to these side effects nor the best ways to address them. Studies that examined lifestyle modification and pharmaceutical agents have yielded mixed results. Therefore, clinical studies using agents, such as vitamin $\mathrm{D}$, which are inexpensive, readily available, with low side effects profile, and have mechanisms to counteract the metabolic side effects of SGA agents, are warranted. Vitamin D is a prohormone with skeletal and extraskeletal properties that could potentially reduce the severity of these metabolic side effects. Its role as an adjunctive therapy for the management of metabolic side effects of SGA agents has not been adequately studied. Effective strategies to curb these side effects will improve the overall health of youths with psychiatric illnesses who receive SGAs. Herein we present a pilot study on the use of vitamin $\mathrm{D}$ in patients on treatment with SGAs.
\end{abstract}

Keywords: antipsychotics; obesity; psychosis; vitamin D.

\footnotetext{
*Corresponding author: Benjamin U. Nwosu, Division of Pediatric Endocrinology, University of Massachusetts Medical School, 55

Lake Ave. North, Worcester, MA 01655, USA

Phone: +508-334-7872, Fax: +508-856-4287,

E-mail: Benjamin.Nwosu@umassmemorial.org

Received June 7, 2011; accepted July 2, 2011; previously

published online August 25, 2011
}

\section{Introduction \\ Second-generation antipsychotic agents and their metabolic side effects}

The atypical or second-generation antipsychotic (SGA) agents were introduced approximately two decades ago. Their reduced incidence of extrapyramidal side effects and reported enhanced therapeutic benefits have rapidly led to their widespread use in the management of various psychiatric illnesses, such as schizophrenia, schizoaffective disorder, and bipolar disorder (1). However, results from studies in adults with schizophrenia, such as the Clinical Antipsychotic Trials of Intervention Effectiveness (CATIE) (2), the Cost Utility of the Latest Antipsychotic Drugs in Schizophrenia Study (CUtLASS) (3), and the European First Episode Schizophrenia Trial (EuFEST) (4), demonstrated rapid and significant weight gain in patients treated with these medications.

There is increasing evidence that SGA agents can increase the risk of metabolic abnormalities in patients (5-8). Metabolic syndrome is a term used to describe the coexistence of obesity, hypertension, dyslipidemia, and insulin resistance or diabetes in an individual, which confers a high degree of risk for cardiovascular disease or earlier mortality (9). The prevalence of metabolic syndrome in patients with chronic schizophrenia is $37 \%$ (8), compared with $24 \%$ in the general population (10). Patients with schizophrenia also have a three-fold increased risk of developing type 2 diabetes when compared with the general population (11).

The Treatment of Early-Onset Schizophrenia Spectrum Disorders (TEOSS) study (12), an 8-week double-blind comparison of first- and second-generation antipsychotics in early onset schizophrenia and schizoaffective disorder demonstrated that children who were treated with SGA agents had early and significant weight gain, similar to that reported for adults. In the TEOSS study, molindone (a firstgeneration antipsychotic medication) was compared with two SGA agents: olanzapine and risperidone. These two SGA agents were not superior to molindone in controlling psychiatric symptoms. Moreover, the investigators found significant increases in body mass index (BMI) with the SGA agents as compared with molindone as shown in Figure 1A. Youths treated with olanzapine gained an average of $6.1 \mathrm{~kg}$ $(\mathrm{SD}=3.6)$ and increased their BMI by an average of $2.2 \mathrm{~kg} / \mathrm{m}^{2}$ $(\mathrm{SD}=1.2)$ over the 8 -week trial. Subjects treated with risperidone gained a mean of $3.7 \mathrm{~kg}$, whereas those on molindone showed no mean changes in weight. Furthermore, the olanzapine group had greater increases in total cholesterol, low- 

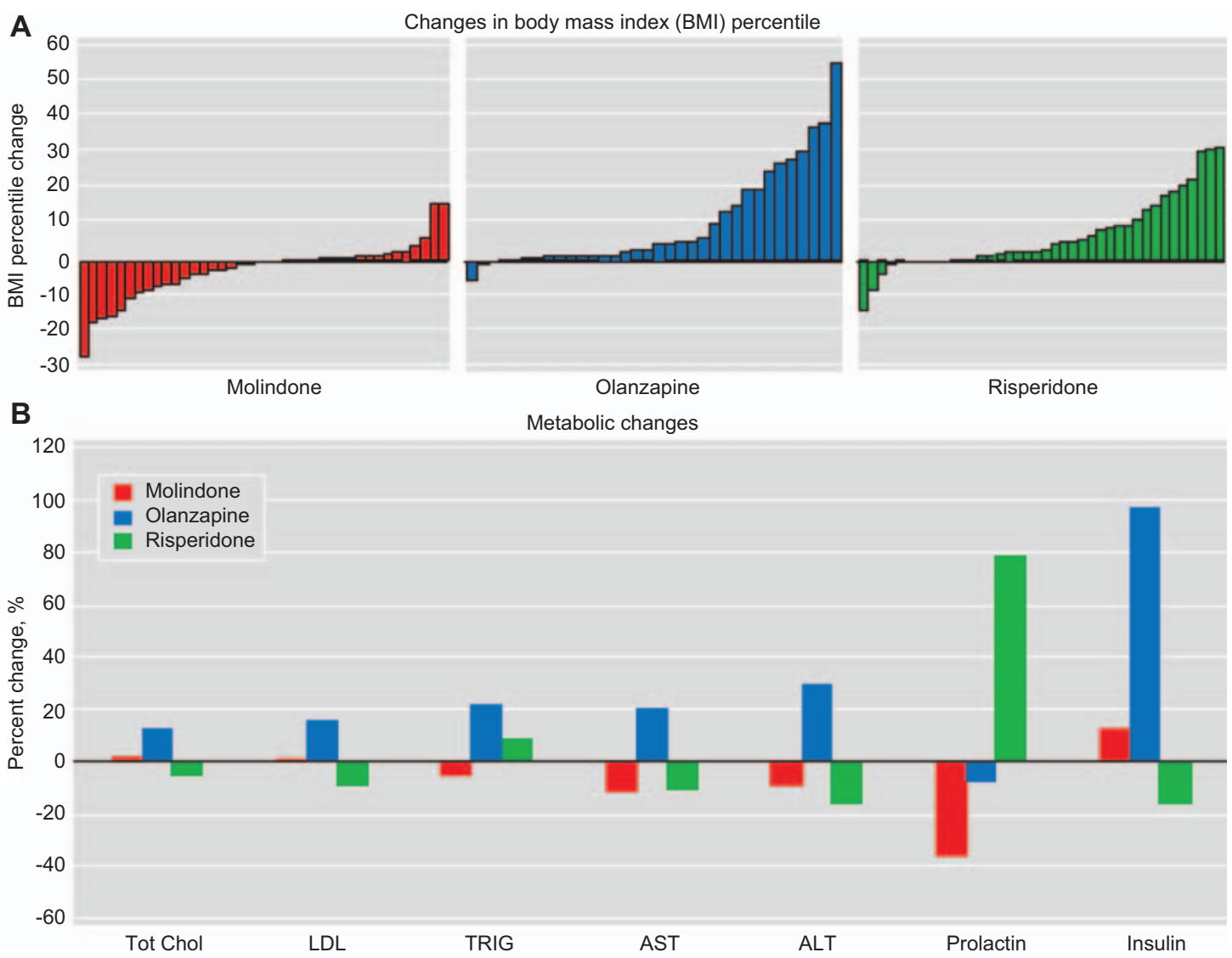

Figure 1 (A) Comparison of changes in BMI percentiles in children who received molindone as compared with those who received olanzapine and risperidone. (B) Comparison of adverse metabolic effect of antipsychotic treatment experienced in subjects with early-onset schizophrenia and schizoaffective disorder (12). Reprinted with permission form the American Journal of Psychiatry (Copyright (C) 2008). American Psychiatric Association.

density lipoprotein cholesterol, and insulin levels, relative to those in the molindone group (Figure 1B), suggesting a propensity for the development of metabolic syndrome. These adverse effects raise important public health concerns given the expanding use of SGA agents in children and adolescents with non-psychotic disorders, such as autism (12).

The nature of body composition changes of SGA agents associated with weight gain in children and adolescents was reported by Correll et al. (13) using bioelectric impedance analysis in a study involving 12 weeks of treatment with aripiprazole, olanzapine, quetiapine, or risperidone in pediatric patients naive to antipsychotic therapy. They reported a weight increase of $8.5 \mathrm{~kg}$ with olanzapine, $6.1 \mathrm{~kg}$ with quetiapine, $5.3 \mathrm{~kg}$ with risperidone, and $4.4 \mathrm{~kg}$ with aripiprazole. Each antipsychotic medication was associated with significant increase in fat mass and waist circumference. In a 6-week randomized, double-blind, placebo-controlled trial of olanzapine vs. placebo in adolescents with schizophrenia, Kryzhanovskaya et al. (14) demonstrated a significant weight gain in adolescents treated with olanzapine compared with placebo ( 4.3 vs. $0.1 \mathrm{~kg}, \mathrm{p}<0.001)$. The weight gain and metabolic side effects lead to reduced compliance rates, and therefore ineffective treatment of the underlying psychiatric illness (15).

\section{Mechanisms of SGA-induced weight gain and metabolic side effects}

The SGAs act by transiently occupying dopamine D2 receptors in the brain and then rapidly dissociating to allow normal dopamine transmission (16). A controversial theory of atypicality proposes that these agents simultaneously block 5-hydroxytryptamine type $2 \mathrm{~A}\left(5-\mathrm{HT}_{2 \mathrm{~A}}\right)$ receptors and dopamine receptors, thus altering the balance of serotonin and dopamine in the brain (16). As a result of the brief D2 receptor blockade, these atypical or SGAs are believed to have enhanced therapeutic benefits and fewer dopamine-related side effects than the typical or first-generation antipsychotic agents, which have greater affinity for the D2 binding site and are associated with high risk for drug-induced movement disorders, such as tardive dyskinesia and other extrapyramidal symptoms $(1,17)$.

The precise mechanism of SGA-induced obesity and its complications is unclear. Some investigators have suggested that this weight gain occurs largely due to an increase in appetite (18). Fadel et al. (19) proposed that the propensity for weight gain while receiving atypical antipsychotic agents was correlated with the degree of Fos induction in orexin neurons of the lateral hypothalamic/perifornical area of 
rats. Orexins are peptides expressed in neurons of the lateral hypothalamus and perifornical area that are potent regulators of feeding and other metabolic processes. Other workers have suggested that because antipsychotic medications have a broad range of activity over central neurotransmitter systems, such as serotonin, dopamine, acetylcholine, and histamine (15), it is possible that their variable antagonistic effects on receptor subtypes, such as $5-\mathrm{HT}_{2 \mathrm{~A}}$, and histamine $1\left(\mathrm{H}_{1}\right)$, which are associated with appetite regulation and body weight, might lead to hyperphagia and obesity (20). Studies have shown that antagonism of serotonin, dopamine, and norepinephrine receptors may be associated with weight gain (21), and a robust correlation has been demonstrated between SGA medication affinity for the $\mathrm{H}_{1}$ receptor and antipsychotic-induced weight gain $(22,23)$. Other reports have proposed abnormal leptin signaling as a contributor to antipsychotic agent-induced weight gain (24-26). Leptin is an adipocyte hormone that regulates food intake and energy balance and correlates closely with total body fat mass and BMI $(27,28)$. Leptin and insulin decrease appetite by inhibiting the production of neuropeptide $\mathrm{Y}$ and agouti-related protein, while stimulating melanocortin-producing neurons in the arcuate nucleus of the hypothalamus. Leptin reduces intracellular lipid concentration by decreasing the synthesis of fatty acid and triglycerides and by increasing lipid oxidation (29). However, studies with adequate statistical power and experimental controls have shown no difference in serum leptin concentrations and expression when confounding variables, such as sex and adiposity are taken into account (30, 31). Other data suggest that elevated prolactin contributes to SGA agent-induced weight gain by reducing insulin sensitivity or by altering the ratio of androgen to estrogen in the body (32).

An alternative proposed mechanism is a direct action of the antipsychotic agents on the pancreatic beta cells. It has been suggested that antipsychotic molecules could antagonize the muscarinic M3 receptors on beta cells, leading to suppression of cholinergic-stimulated insulin secretion. This will in turn inhibit glucose transport into peripheral tissues leading to hyperglycemia (33). This SGA agent-induced deficit in betacell function is believed to be due to a combination of increased insulin resistance and decreased glucose-stimulated insulin secretion (34). Other possible mechanisms include induction of peripheral insulin resistance, impairment of beta-cell function by serotonergic $\left(5-\mathrm{HT}_{1 \mathrm{~A} / 2 \mathrm{~A} / 2 \mathrm{C}}\right)$ receptor antagonism, inhibition of beta-cell function via alpha 2-adrenergic receptors, or by direct toxic effects on beta cells $(35,36)$. The serotonergic receptors, especially the $5-\mathrm{HT}_{2 \mathrm{c}}$ receptors, are believed to be candidate target receptors for psychotropic-induced weight gain, as their antagonism leads to weight gain $(20,37)$.

Thus, to date, there is no consensus on the mechanism of SGA-mediated weight gain, as all of the above mechanisms are speculative. One potential mechanism that has not been explored is the role of vitamin D deficiency in the propagation of SGA-mediated obesity. This is informed by studies suggesting that serum vitamin D concentrations might have a direct effect on body weight. Sibley (38) demonstrated a correlation between weight loss and vitamin D levels in an 11-week study of 38 patients on caloric restriction diets who lost $0.196 \mathrm{~kg}$ for every $1 \mathrm{ng} / \mathrm{mL}$ increase in serum concentrations of 25-hydroxyvitamin D (25-OHD). They also showed that higher levels of 25-OHD at baseline predicted increased abdominal subcutaneous fat loss.

\section{Current modalities of management of SGA-induced weight gain and metabolic side effects}

Various modalities and medications have been proposed as adjunctive therapies to attenuate the weight gain associated with treatment with SGA agents. Studies examining the effects of lifestyle interventions and pharmaceutical agents, such as sibutramine (39), metformin (40-44), orlistat (45), amantadine (46), and topiramate (47) have had mixed results. Moreover, sibutramine is now unavailable, and the use of orlistat is limited by its severe gastrointestinal and systemic side effects. Lifestyle interventions, such as psychoeducational, dietary, and exercise programs can be effective in the short term (48), but no large-scale study has been performed to evaluate long-term effectiveness (15), and lifestyle interventions are difficult to sustain, especially for individuals with severe psychiatric illness. In general, pharmacologic treatment modalities for weight loss are sparse with only a few Food and Drug Administration-approved medications. Even then, some of these approved medications stimulate central serotonin and norepinephrine systems (49), a mechanism of action that is opposite to the desired actions of the SGA agents.

In a randomized, double-blind, placebo-controlled trial, Klein et al. (42) studied the effectiveness of metformin in managing weight gain associated with the initiation of SGA agents in children and adolescents, ages 10-17 years, who had gained $>10 \%$ of body weight during $<1$ year of olanzapine, risperidone, or quetiapine therapy. They reported the children treated with placebo continued to gain weight at a rate of $0.31 \mathrm{~kg} /$ week (mean=4.01 kg, $\mathrm{SD}=6.23$ ), over 16 weeks, despite three family sessions of dietary counseling. In contrast, the weight of the subjects treated with metformin showed little change over the treatment period (mean $-0.13 \mathrm{~kg}, \mathrm{SD}=2.88$ ).

In a 12-week, open-label trial of metformin for the treatment of weight gain and metabolic profiles in pediatric patients, Shin et al. (50) studied 11 children and adolescents ages $10-18$ years who received metformin orally up to $2000 \mathrm{mg} /$ day. They reported no statistically significant reductions in mean weight, waist circumference, BMI, serum glucose, and insulin even though 5 of the 11 subjects lost weight. This is in contrast to another open-label metformin study by Morrison et al. (40) who studied 19 patients of ages 10-18 years for 12 weeks. In this study, 15 subjects lost weight, 3 gained weight, and 1 patient had no weight change. They reported a significant decrease in mean weight $(-2.93 \mathrm{~kg}, \mathrm{SD}=3.13$, $\mathrm{p}=0.008)$ and BMI $\left(-2.22 \mathrm{~kg} / \mathrm{m}^{2}, \mathrm{SD}=1.98, \mathrm{p}=0.003\right)$ at 12 weeks.

Although these small studies are promising, there is no consensus recommendation supporting the use of metformin in the management of weight gain associated with SGA 
agents. The use of metformin is limited by its gastrointestinal side effects, which include stomach upset and nausea; contraindication in patients with renal and hepatic dysfunction, and concerns regarding its rare but severe side effect of lactic acidosis. Therefore, alternative safe and inexpensive agents with a high safety profile that has efficacy in preventing SGAmediated weight gain would be a valuable adjunct to the management of children with psychiatric disorders requiring SGA therapy.

\section{Vitamin D}

\section{General effects of vitamin D}

Vitamin D is a safe, well-tolerated, and easily available agent with no central stimulatory properties. Its primary skeletal function is the promotion of calcium absorption from the gut and phosphorus reabsorption from the kidneys for the maintenance of the skeleton (51). Although controversial (52), there are many reports of extraskeletal effects of vitamin D, such as boosting of immune system by modulating B- and T-lymphocyte function (53), prevention of certain malignancies, such as colon cancer (54), the association of a reduction in the prevalence of psychiatric illnesses, such as schizophrenia in offspring of vitamin D-sufficient mothers (55), and the prevention of diabetes mellitus (56).

\section{Effects of vitamin D on glucose metabolism}

Normal insulin secretion is partly dependent on 1,25-dihyroxyvitamin $\mathrm{D}\left(1,25(\mathrm{OH})_{2} \mathrm{D}_{3}\right)$ concentrations in both intact animals and isolated islets $(57,58)$. Limited evidence suggests that vitamin D deficiency increases insulin resistance and thus may play a role in the early stages of the development of type 2 diabetes (59). Low serum vitamin D concentrations correlate with impaired glucose tolerance (60-63), whereas administration of supplemental vitamin D to subjects with elevated blood glucose levels increases insulin secretion $(64,65)$. Similar improvements have been observed in vitamin D-deficient subjects following supplementation $(61,66)$. Even though there are reports of a correlation between hypovitaminosis D and insulin resistance in obese adolescents (67), clinical trials with vitamin D supplementation are sparse $(59,65,68)$, especially in patients with psychiatric illnesses who receive adipogenic SGA agents.

The circulating concentration of 25-OHD is regarded as the best index of nutritional vitamin D status. There are differing definitions for suboptimal serum concentration of 25-OHD (51). In general, hypovitaminosis D is defined as serum 25-OHD concentrations $<75 \mathrm{mmol} / \mathrm{L}(31.25 \mathrm{ng} / \mathrm{mL})$, and vitamin D deficiency as serum 25-OHD concentration $<50 \mathrm{nmol} / \mathrm{L}(20.8 \mathrm{ng} / \mathrm{mL})(67)$.

Vitamin D deficiency has been reported in obese individuals (69-72), although the etiology is unclear. Proposed causative factors include poor general nutrition, which results from low intake of vitamin D-containing foods, such as salmon, inadequate exposure to sunlight, and the sequestration of vitamin
$\mathrm{D}$ in fat stores in obese individuals, which makes the vitamin D unavailable for biological activities (70).

It is possible that vitamin D deficiency acts synergistically with other pathways to propagate the weight gain associated with SGA agents. Although a direct catabolic effect on vitamin D molecule by SGA agents has not been demonstrated, certain drugs directly impair vitamin D metabolism and reduce its levels. Pascussi et al. (73) conducted both in vivo (using human hepatocytes) and in vitro (in mice) experiments showing that antiepileptic drugs that activate pregnane $\mathrm{X}$ receptor (PXR) enhance CYP24 expression and accelerate the catabolism of 25-OHD, leading to vitamin D deficiency. Similarly, xenobiotic drugs, including rifampin, glucocorticoids, and antiretroviral drugs, may induce vitamin D deficiency through the same pathway (74). It is likely that other families of drugs also are activators of PXR and may increase vitamin D catabolism (74) in the liver, leading to vitamin D deficiency and osteomalacia $(73,75)$. Interestingly, treatment with SGA agents has also been associated with both vitamin D deficiency and osteomalacia $(76,77)$. Given the above findings, it is possible that SGA agents might activate PXR and induce vitamin $\mathrm{D}$ deficiency, which in turn results in weight accrual.

\section{Central and peripheral mechanisms of the antiobesity effects of vitamin D}

Peripheral mechanism Vitamin D deficiency is marked by low serum 25-OHD and elevated parathyroid hormone (PTH) and $1,25(\mathrm{OH})_{2} \mathrm{D}_{3}(70-72,78)$ to maintain normocalcemia. This compensatory increase in $1,25(\mathrm{OH})_{2} \mathrm{D}_{3}$ level is the principal proposed mechanism of vitamin $\mathrm{D}$ deficiency-related adipogenesis. Elevated serum concentrations of $1,25(\mathrm{OH})_{2} \mathrm{D}_{3}$ are believed to promote obesity by binding to a membrane vitamin D receptor called the membrane-associated rapid response to steroid receptor $(79,80)$ and inducing a rapid influx of calcium ions into adipocytes (Figure 2). Intracellular $\mathrm{Ca}^{2+}$, a key regulator of adipocyte lipid metabolism, stimulates the expression and activity of fatty acid synthase (FAS), a key enzyme for de novo lipogenesis, while inhibiting basal and agonist-stimulated lipolysis in adipocytes (81). This results in increased lipid accumulation in adipocytes (82) and attendant obesity, which leads to a further decrease in 25-OHD as a result of sequestration of vitamin $\mathrm{D}$ in fat depots. This establishes a vicious cycle of worsening obesity and vitamin $\mathrm{D}$ deficiency.

Therefore, pharmacologic interventions aimed at normalizing serum concentrations of 25-OHD may prevent both PTH elevation and compensatory activation of 25-OHD to 1,25 $(\mathrm{OH})_{2} \mathrm{D}_{3}$, which in turn will preclude the elevation of intracellular calcium ion concentrations and consequently reduces the activity of FAS. This breaks the vicious cycle of obesity and vitamin $\mathrm{D}$ deficiency.

Central mechanism FAS activity is present peripherally in adipocytes and centrally in the hypothalamus $(81,83)$. Hypothalamic fatty acid metabolism plays a major role in the modulation of energy balance, affecting both feeding and energy expenditure (84). Treatments with FAS inhibitors, such 


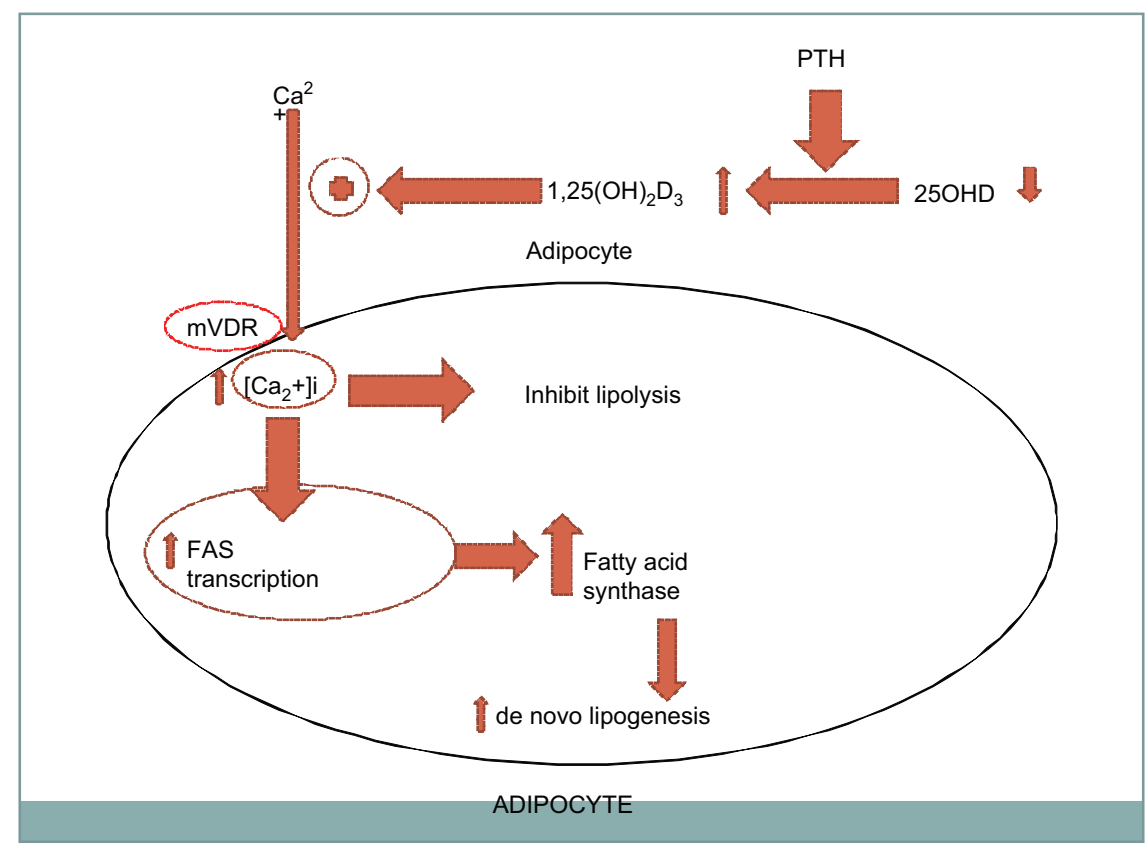

Figure 2 In vitamin D-deficient states, PTH accelerates the conversion of $25-\mathrm{OHD}$ to $1,25(\mathrm{OH})_{2} \mathrm{D}_{3}$, which results in a compensatory increase in serum 1,25-dihydroxyvitamin D level, which drives the influx of calcium ions into the cell and consequent activation of FAS. Adapted from Zemel (81).

as cerulenin, or drugs that down-regulate FAS expression, such as tamoxifen, induce remarkable weight loss and hypophagia (85). The anorectic effect of these drugs requires the accumulation of malonyl-CoA in the hypothalamus, which may serve as a signal of nutrient abundance by critical neurons regulating food intake (84), decreased expression of orexigenic (agouti-related protein, neuropeptide Y), and elevated expression of anorexigenic (cocaine- and amphetamineregulated transcript, proopiomelanocortin) neuropeptides in the arcuate nucleus $(86,87)$. It is possible, therefore, to induce similar effects as drugs that down-regulate FAS activity by preventing the up-regulation of FAS through optimal vitamin D supplementation. One study demonstrated a correlation between weight loss and vitamin $\mathrm{D}$ levels in adults receiving caloric restriction diets who lost $0.196 \mathrm{~kg}$ for every $1 \mathrm{ng} / \mathrm{mL}$ increase in serum concentrations of 25-OHD (38).

\section{A feasibility study on the role of vitamin $D$ in patients receiving SGAs}

Given the paucity of data on the role of vitamin D supplementation in children and adolescents with SGA-induced obesity, we designed a feasibility study to evaluate the relationship between changes in anthropometry and serum concentrations of 25-OHD in overweight and obese patients on treatment with SGA agents. Our primary objective was to establish the feasibility of enrolling adolescents with major psychiatric disorders in an in-patient setting in a treatment study. Our secondary aim was to conduct an open-label pilot study to determine the safety profile and efficacy of supplemental vitamin D in psychiatric patients receiving SGA medications. We believed that the results of such a study would form the framework for the development of a longer-term clinical study.

All subjects had a Diagnostic and Statistical Manual of Mental Disorders, Fourth Edition (88) Axis 1 diagnosis and had been receiving treatment with SGA medication for more than 3 months. All had a BMI of $>85$ th percentile and had a 25-hydroxyvitamin D level of $<75 \mathrm{nmol} / \mathrm{L}(30 \mathrm{ng} / \mathrm{mL})$. Subjects were excluded from participation if they met the criteria for an eating disorder, substance abuse/dependence, significant medical or neurological illness, IQ $<70$, pregnancy, recent history of suicidality, or being psychiatrically unstable on their current medication regimen. The study was approved by the University of Massachusetts Medical School and the Department of Mental Health Services Institutional Review Boards. Signed parental informed consent with signed assent of the youth were obtained before study enrollment and baseline eligibility assessment.

All participants were residents of a chronic care facility for adolescents with psychiatric disorders. All received 10 drops (2000 IU) of ergocalciferol every morning before breakfast for 8 weeks. Anthropometric measures, height $(\mathrm{cm})$, weight $(\mathrm{kg}), \mathrm{BMI}\left(\mathrm{kg} / \mathrm{m}^{2}\right)$, as well as laboratory evaluations were performed in the fasting state.

Of the 12 participants, 4 were males and 8 were females. Of these, eight were white, two were Hispanic, and two were African American. All participants completed the study. The average age was $16.6 \pm 1.65$ years, with a range of $13-18$ years. At the end of the study, there was a non-significant decrease in body weight standard deviation score from baseline to the end 
of study, $2.56 \pm 1.32$ vs. $2.49 \pm 1.38$ ( $\mathrm{p}=0.18)$ ( $95 \%$ confidence interval -0.200 to 0.058 ). One subject experienced no change in weight, five subjects gained weight, and six subjects lost weight. When analyzed by sex, two males gained weight, one lost weight, and one had no weight change. Three females gained weight, whereas five lost weight. Serum concentrations of 25-OHD increased significantly from baseline to the end of study $46.5 \pm 18.65$ vs. $72.75 \pm 21.12 \mathrm{nmol} / \mathrm{L}(18.6 \pm 7.46$ vs. $29.1 \pm 8.45 \mathrm{ng} / \mathrm{mL})(\mathrm{p}=0.0001)$. There were no side effects from the vitamin D supplementation. Thus, we achieved our primary objective, which was to establish the feasibility of enrolling adolescents with major psychiatric disorders in an in-patient setting in a treatment study. We also demonstrated that adjunctive vitamin D supplementation is safe in psychiatric patients receiving SGA medications. We did not design the study with sufficient power or long enough duration to detect significant changes in weight or BMI, as this was a feasibility study. We are now planning a trial of longer duration with vitamin D supplementation, which is inexpensive, readily available, with a low side effect profile, which could counteract the metabolic side effects of SGA agents.

\section{Summary and conclusion}

In summary, SGA medications are increasingly being prescribed to treat psychiatric illnesses in children and adolescents. However, the use of these agents is limited by their severe metabolic side effects. The mechanism(s) of these adverse events are unknown, and there is a lack of consensus on the best approach to address these problems. In conclusion, adjunctive vitamin $\mathrm{D}$ therapy may play a role in counteracting the adipogenic effects of SGA agents.

\section{References}

1. Wilson DR, D'Souza L, Sarkar N, Newton M, Hammond C. New-onset diabetes and ketoacidosis with atypical antipsychotics. Schizophr Res 2002;59:1-6.

2. Lieberman JA, Stroup TS, McEvoy JP, Swartz MS, Rosenheck RA, et al. Effectiveness of antipsychotic drugs in patients with chronic schizophrenia. N Engl J Med 2005;353:1209-23.

3. Jones PB, Barnes TR, Davies L, Dunn G, Lloyd H, et al. Randomized controlled trial of the effect on quality of life of second- vs. first-generation antipsychotic drugs in schizophrenia: Cost Utility of the Latest Antipsychotic Drugs in Schizophrenia Study (CUtLASS 1). Arch Gen Psychiatry 2006;63:1079-87.

4. Kahn RS, Fleischhacker WW, Boter H, Davidson M, Vergouwe $\mathrm{Y}$, et al. Effectiveness of antipsychotic drugs in first-episode schizophrenia and schizophreniform disorder: an open randomised clinical trial. Lancet 2008;371:1085-97.

5. Haupt DW. Differential metabolic effects of antipsychotic treatments. Eur Neuropsychopharmacol 2006;16(Suppl 3):S149-55.

6. Dixon L, Weiden P, Delahanty J, Goldberg R, Postrado L, et al. Prevalence and correlates of diabetes in national schizophrenia samples. Schizophr Bull 2000;26:903-12.

7. Basu R, Brar JS, Chengappa KN, John V, Parepally H, et al. The prevalence of the metabolic syndrome in patients with schizoaffective disorder-bipolar subtype. Bipolar Disord 2004;6:314-8.
8. Heiskanen T, Niskanen L, Lyytikainen R, Saarinen PI, Hintikka J. Metabolic syndrome in patients with schizophrenia. J Clin Psychiatry 2003;64:575-9.

9. Diabetes and obesity: time to act. Brussels: Federation TID, 2004.

10. Ford ES, Giles WH, Dietz WH. Prevalence of the metabolic syndrome among US adults: findings from the third National Health and Nutrition Examination Survey. J Am Med Assoc 2002;287:356-9.

11. Lorenzo C, Okoloise M, Williams K, Stern MP, Haffner SM. The metabolic syndrome as predictor of type 2 diabetes: the San Antonio Heart Study. Diabetes Care 2003;26:3153-9.

12. Sikich L, Frazier JA, McClellan J, Findling RL, Vitiello B, et al. Double-blind comparison of first- and second-generation antipsychotics in early-onset schizophrenia and schizo-affective disorder: findings from the Treatment of Early-Onset Schizophrenia Spectrum Disorders (TEOSS) Study. Am J Psychiatry 2008;165:1420-31.

13. Correll CU, Manu P, Olshanskiy V, Napolitano B, Kane JM, et al. Cardiometabolic risk of second-generation antipsychotic medications during first-time use in children and adolescents. J Am Med Assoc 2009;302:1765-73.

14. Kryzhanovskaya L, Schulz SC, McDougle C, Frazier J, Dittmann $\mathrm{R}$, et al. Olanzapine versus placebo in adolescents with schizophrenia: a 6-week, randomized, double-blind, placebo-controlled trial. J Am Acad Child Adolesc Psychiatry 2009;48:60-70.

15. Makimura H. Obesity and antipsychotic drug use. MGH Neuroendocrine Clinical Center Bulletin 2008;14:4-5.

16. Seeman P, Tallerico T, Ko F. Dopamine displaces [3H]domperidone from high-affinity sites of the dopamine D2 receptor, but not $[3 \mathrm{H}]$ raclopride or $[3 \mathrm{H}]$ spiperone in isotonic medium: implications for human positron emission tomography. Synapse 2003;49:209-15.

17. Caroff SN, Hurford I, Lybrand J, Campbell EC. Movement disorders induced by antipsychotic drugs: implications of the CATIE schizophrenia trial. Neurol Clin 2011;29:127-48, viii.

18. Henderson DC. Weight gain with atypical antipsychotics: evidence and insights. J Clin Psychiatry 2007;68(Suppl 12):18-26.

19. Fadel J, Bubser M, Deutch AY. Differential activation of orexin neurons by antipsychotic drugs associated with weight gain. $\mathrm{J}$ Neurosci 2002;22:6742-6.

20. Tecott LH, Sun LM, Akana SF, Strack AM, Lowenstein DH, et al. Eating disorder and epilepsy in mice lacking 5-HT2c serotonin receptors. Nature 1995;374:542-6.

21. Stahl SM. Neuropharmacology of obesity: my receptors made me eat it. J Clin Psychiatry 1998;59:447-8.

22. Wirshing DA, Wirshing WC, Kysar L, Berisford MA, Goldstein $\mathrm{D}$, et al. Novel antipsychotics: comparison of weight gain liabilities. J Clin Psychiatry 1999;60:358-3.

23. Richelson E. Preclinical pharmacology of neuroleptics: focus on new generation compounds. J Clin Psychiatry 1996;57(Suppl 11):4-11.

24. Kraus T, Haack M, Schuld A, Hinze-Selch D, Kühn M, et al. Body weight and leptin plasma levels during treatment with antipsychotic drugs. Am J Psychiatry 1999;156:312-4.

25. Melkersson KI, Hulting AL, Brismar KE. Elevated levels of insulin, leptin, and blood lipids in olanzapine-treated patients with schizophrenia or related psychoses. J Clin Psychiatry 2000;61:742-9.

26. Hagg S, Soderberg S, Ahren B, Olsson T, Mjorndal T. Leptin concentrations are increased in subjects treated with clozapine or conventional antipsychotics. J Clin Psychiatry 2001;62: 843-8. 
27. Prolo P, Wong ML, Licinio J. Leptin. Int J Biochem Cell Biol 1998;30:1285-90.

28. Atmaca M, Kuloglu M, Tezcan E, Ustundag B. Serum leptin and triglyceride levels in patients on treatment with atypical antipsychotics. J Clin Psychiatry 2003;64:598-604.

29. Auwerx J, Staels B. Leptin. Lancet 1998;351:737-42.

30. Herran A, Garcia-Unzueta MT, Amado JA, de La Maza MT, Alvarez C, et al. Effects of long-term treatment with antipsychotics on serum leptin levels. Br J Psychiatry 2001;179:59-62.

31. Haupt DW, Luber A, Maeda J, Melson AK, Schweiger JA, et al. Plasma leptin and adiposity during antipsychotic treatment of schizophrenia. Neuropsychopharmacology 2005;30:184-91.

32. McIntyre RS, Mancini DA, Basile VS. Mechanisms of antipsychotic-induced weight gain. J Clin Psychiatry 2001;62(Suppl 23):23-9.

33. Houseknecht KL, Robertson AS, Zavadoski W, Gibbs EM, Johnson DE, et al. Acute effects of atypical antipsychotics on whole-body insulin resistance in rats: implications for adverse metabolic effects. Neuropsychopharmacology 2007;32: 289-97.

34. Chintoh AF, Mann SW, Lam L, Lam C, Cohn TA, et al. Insulin resistance and decreased glucose-stimulated insulin secretion after acute olanzapine administration. J Clin Psychopharmacol 2008;28:494-9.

35. Schwenkreis P, Assion HJ. Atypical antipsychotics and diabetes mellitus. World J Biol Psychiatry 2004;5:73-82.

36. Goldstein LE, Sporn J, Brown S, Kim H, Finkelstein J, et al. New-onset diabetes mellitus and diabetic ketoacidosis associated with olanzapine treatment. Psychosomatics 1999;40: 438-43.

37. Vickers SP, Benwell KR, Porter RH, Bickerdike MJ, Kennett $\mathrm{GA}$, et al. Comparative effects of continuous infusion of $\mathrm{mCPP}$, Ro 60-0175 and D-fenfluramine on food intake, water intake, body weight and locomotor activity in rats. $\mathrm{Br} \mathrm{J}$ Pharmacol 2000;130:1305-14.

38. Sibley SD. Plasma vitamin D predicted weight loss in obese individuals. In: The Endocrine Society's 91st Annual Meeting, June 10-13, 2009, Washington, DC, 2009.

39. Henderson DC, Copeland PM, Daley TB, Borba CP, Cather C, et al. A double-blind, placebo-controlled trial of sibutramine for olanzapine-associated weight gain. Am J Psychiatry 2005;162:954-62.

40. Morrison JA, Cottingham EM, Barton BA. Metformin for weight loss in pediatric patients taking psychotropic drugs. Am J Psychiatry 2002;159:655-7.

41. Shin L, Breeze J, Noyes N, Frazier JA. Metformin for weight control in pediatric patients on atypical antipsychotic medications. J Child Adolesc Psychopharmacol 2009;19:275-9.

42. Klein DJ, Cottingham EM, Sorter M, Barton BA, Morrison JA. A randomized, double-blind, placebo-controlled trial of metformin treatment of weight gain associated with initiation of atypical antipsychotic therapy in children and adolescents. Am J Psychiatry 2006;163:2072-9.

43. Baptista T, Martinez J, Lacruz A, Rangel N, Beaulieu S, et al. Metformin for prevention of weight gain and insulin resistance with olanzapine: a double-blind placebo-controlled trial. Can J Psychiatry 2006;51:192-6.

44. Wu RR, Zhao JP, Liu ZN, Zhai JG, Guo XF, et al. Effects of typical and atypical antipsychotics on glucose-insulin homeostasis and lipid metabolism in first-episode schizophrenia. Psychopharmacology (Berl) 2006;186:572-8.

45. Joffe G, Takala P, Tchoukhine E, Hakko H, Raidma M, et al. Orlistat in clozapine- or olanzapine-treated patients with overweight or obesity: a 16-week randomized, double-blind, placebo-controlled trial. J Clin Psychiatry 2008;69:706-11.

46. Graham KA, Gu H, Lieberman JA, Harp JB, Perkins DO. Double-blind, placebo-controlled investigation of amantadine for weight loss in subjects who gained weight with olanzapine. Am J Psychiatry 2005;162:1744-6.

47. Canitano R. Clinical experience with topiramate to counteract neuroleptic induced weight gain in 10 individuals with autistic spectrum disorders. Brain Dev 2005;27:228-32.

48. Knox JM. A study of weight reducing diets in psychiatric in-patients. Br J Psychiatry 1980;136:287-9.

49. Eckel RH. Clinical practice. Nonsurgical management of obesity in adults. N Engl J Med 2008;358:1941-50.

50. Shin L, Bregman H, Breeze JL, Noyes N, Frazier JA. Metformin for weight control in pediatric patients on atypical antipsychotic medication. J Child Adolesc Psychopharmacol 2009;19:275-9.

51. Misra M, Pacaud D, Petryk A, Collett-Solberg PF, Kappy M. Vitamin D deficiency in children and its management: review of current knowledge and recommendations. Pediatrics 2008; $122: 398-417$.

52. Ross AC, Manson JE, Abrams SA, Aloia JF, Brannon PM, et al. The 2011 report on dietary reference intakes for calcium and vitamin $\mathrm{d}$ from the institute of medicine: what clinicians need to know. J Clin Endocrinol Metab 2011;96:53-8.

53. Tsoukas CD, Provvedini DM, Manolagas SC. 1,25-Dihydroxyvitamin D3: a novel immunoregulatory hormone. Science 1984;224:1438-40.

54. Pritchard RS, Baron JA, Gerhardsson de Verdier M. Dietary calcium, vitamin D, and the risk of colorectal cancer in Stockholm, Sweden. Cancer Epidemiol Biomarkers Prev 1996;5:897-900.

55. Rasanen P, Hakko H, Jarvelin MR. Prenatal and perinatal risk factors for psychiatric diseases of early onset. Results are different if seasons are categorised differently. Br Med J 1999;318:1622-3.

56. Hypponen E, Laara E, Reunanen A, Jarvelin MR, Virtanen SM. Intake of vitamin D and risk of type 1 diabetes: a birth-cohort study. Lancet 2001;358:1500-3.

57. Norman AW, Frankel JB, Heldt AM, Grodsky GM. Vitamin D deficiency inhibits pancreatic secretion of insulin. Science 1980;209:823-5.

58. Kadowaki S, Norman AW. Dietary vitamin D is essential for normal insulin secretion from the perfused rat pancreas. J Clin Invest 1984;73:759-66.

59. von Hurst PR, Stonehouse W, Matthys C, Conlon C, Kruger MC, et al. Study protocol - metabolic syndrome, vitamin $\mathrm{D}$ and bone status in South Asian women living in Auckland, New Zealand: a randomised, placebo-controlled, double-blind vitamin D intervention. BMC Public Health 2008;8:267.

60. Lucas JA, Bolland MJ, Grey AB, Ames RW, Mason BH, et al. Determinants of vitamin D status in older women living in a subtropical climate. Osteoporos Int 2005;16:1641-8.

61. Boucher BJ, Mannan N, Noonan K, Hales CN, Evans SJ. Glucose intolerance and impairment of insulin secretion in relation to vitamin D deficiency in east London Asians. Diabetologia 1995;38:1239-45.

62. Isaia G, Giorgino R, Adami S. High prevalence of hypovitaminosis D in female type 2 diabetic population. Diabetes Care 2001;24:1496.

63. Scragg R, Holdaway I, Singh V, Metcalf P, Baker J, et al. Serum 25-hydroxyvitamin D3 levels decreased in impaired glucose tolerance and diabetes mellitus. Diabetes Res Clin Pract 1995;27:181-8. 
64. Kumar S, Davies M, Zakaria Y, Mawer EB, Gordon C, et al. Improvement in glucose tolerance and beta-cell function in a patient with vitamin $\mathrm{D}$ deficiency during treatment with vitamin D. Postgrad Med J 1994;70:440-3

65. Borissova AM, Tankova T, Kirilov G, Dakovska L, Kovacheva $R$. The effect of vitamin D3 on insulin secretion and peripheral insulin sensitivity in type 2 diabetic patients. Int J Clin Pract 2003;57:258-61.

66. Gedik O, Akalin S. Effects of vitamin D deficiency and repletion on insulin and glucagon secretion in man. Diabetologia 1986;29:142-5.

67. Alemzadeha R, Kichlerb J, Babara G, Calhouna M. Hypovitaminosis D in obese children and adolescents: relationship with adiposity, insulin sensitivity, ethnicity, and season. Metabolism 2008;57:183-91.

68. Pittas AG, Harris SS, Stark PC, Dawson-Hughes B. The effects of calcium and vitamin D supplementation on blood glucose and markers of inflammation in nondiabetic adults. Diabetes Care 2007;30:980-6.

69. Parikh SJ, Edelman M, Uwaifo GI, Freedman RJ, SemegaJanneh $\mathrm{M}$, et al. The relationship between obesity and serum 1,25-dihydroxy vitamin D concentrations in healthy adults. J Clin Endocrinol Metab 2004;89:1196-9.

70. Liel Y, Ulmer E, Shary J, Hollis BW, Bell NH. Low circulating vitamin D in obesity. Calcif Tissue Int 1988;43:199-201.

71. Bell NH, Epstein S, Greene A, Shary J, Oexmann MJ, et al. Evidence for alteration of the vitamin D-endocrine system in obese subjects. J Clin Invest 1985;76:370-3.

72. Zamboni G, Soffiati M, Giavarina D, Tato L. Mineral metabolism in obese children. Acta Paediatr Scand 1988;77: 741-6.

73. Pascussi JM, Robert A, Nguyen M, Walrant-Debray O, Garabedian M, et al. Possible involvement of pregnane $\mathrm{X}$ receptor-enhanced CYP24 expression in drug-induced osteomalacia. J Clin Invest 2005;115:177-86.

74. Holick MF. Stay tuned to PXR: an orphan actor that may not be D-structive only to bone. J Clin Invest 2005;115:32-4.

75. Karaaslan Y, Haznedaroglu S, Ozturk M. Osteomalacia associated with carbamazepine/valproate. Ann Pharmacother 2000;34: 264-5.
76. Cardinal RN, Gregory CA. Osteomalacia and vitamin D deficiency in a psychiatric rehabilitation unit: case report and survey. BMC Res Notes 2009;2:82.

77. Rehman HU. Persistently raised alkaline phosphatase in a woman with osteomalacia. Br Med J 2009;338:b1874.

78. Hey H, Stokholm KH, Lund B, Lund B, Sorensen OH. Vitamin $\mathrm{D}$ deficiency in obese patients and changes in circulating vitamin $\mathrm{D}$ metabolites following jejunoileal bypass. Int $\mathrm{J}$ Obes 1982;6:473-9.

79. Zemel MB, Sun X. Calcitriol and energy metabolism. Nutr Rev 2008;66:S139-46.

80. Rohe B, Safford SE, Nemere I, Farach-Carson MC. Identification and characterization of 1,25D3-membrane-associated rapid response, steroid (1,25D3-MARRS)-binding protein in rat IEC-6 cells. Steroids 2005;70:458-63.

81. Zemel MB. Regulation of adiposity and obesity risk by dietary calcium: mechanisms and implications. J Am Coll Nutr 2002;21:146S-51S

82. Shi H, Norman AW, Okamura WH, Sen A, Zemel MB. 1alpha,25Dihydroxyvitamin D3 modulates human adipocyte metabolism via nongenomic action. FASEB J 2001;15:2751-3.

83. Martinez de Morentin PB, Varela L, Ferno J, Nogueiras R, Dieguez C, et al. Hypothalamic lipotoxicity and the metabolic syndrome. Biochim Biophys Acta 2010;1801:350-61.

84. Lane MD, Wolfgang M, Cha SH, Dai Y. Regulation of food intake and energy expenditure by hypothalamic malonyl-CoA. Int J Obes (Lond) 2008;32(Suppl 4):S49-54.

85. Lopez M, Lelliott CJ, Tovar S, Kimber W, Gallego R, et al. Tamoxifen-induced anorexia is associated with fatty acid synthase inhibition in the ventromedial nucleus of the hypothalamus and accumulation of malonyl-CoA. Diabetes 2006;55: 1327-36.

86. Gao S, Lane MD. Effect of the anorectic fatty acid synthase inhibitor $\mathrm{C} 75$ on neuronal activity in the hypothalamus and brainstem. Proc Natl Acad Sci USA 2003;100:5628-33.

87. Shimokawa T, Kumar MV, Lane MD. Effect of a fatty acid synthase inhibitor on food intake and expression of hypothalamic neuropeptides. Proc Natl Acad Sci USA 2002;99:66-71.

88. APA diagnostic criteria from DSM-IV-TR. Washington, DC: American Psychiatric Association, 2000. 